\title{
LA DECADENCIA Y EL AMANECER: UN ANÁLISIS BLOCHIANO DE LA ESPERANZA EN DER TOD IN VENEDIG
}

\author{
María Belforte $^{1}$
}

\begin{abstract}
Resumen:
El presente artículo se propone analizar Der Tod in Venedig (1912), de Thomas Mann, desde la perspectiva filosófica de Ernst Bloch (1885-1977). Para ello se parte de la hipótesis de que existen elementos utópicos puestos en juego en la Novelle y que dichos elementos resignifican la interpretación de la muerte del protagonista, Gustav Aschenbach. Para este análisis se retoman las lecturas de György Lukács (1885-1971) sobre la producción de Mann como exponente de la conciencia burguesa y se discute su lectura sobre la ausencia de lo utópico en la literatura de Mann. Se estudian para ello las implicancias del miedo, la juventud y la esperanza en la obra de 1912. Asimismo se examinan la clasificación y estudio blochianos de los "afectos de la espera" (Erwartungsaffekte) en positivos y negativos así como las consecuencias ontológicas implicadas en la diferenciación de los conceptos de Stimmung y Befindlichkeit en la filosofía de Bloch.
\end{abstract}

Palabras clave: Muerte. Ernst Bloch. Utopía. Erwartungsaffekt. Esperanza.

\section{DECLINE AND DAWN: A BLOCHIAN ANALYSIS OF HOPE IN DER TOD IN VENEDIG}

\begin{abstract}
:
This paper aims at analyzing Der Tod in Venedig (1912) by Thomas Mann from the perspective of Ernst Bloch's (1885-1977) philosophy of hope. The hypothesis is that there are utopian elements in the Novelle which are able to provide a new meaning to the interpretation of the main character's death, Gustav Aschenbach. To such purpose, György Lukács' readings on Mann as epitome of bourgeois conscience are here examined and his hypothesis of the absence of Utopianism in Mann's literature is disputed. It is also studied the presence of fear, youth and hope in the novella. Finally, the article analyzes the Blochian classification and study of positive and negative "expectant emotions" (Erwartungsaffekte) as well as the ontological consequences of distinguishing Stimmung from Befindlichkeit in his philosophy.
\end{abstract}

Keywords: Death. Ernst Bloch. Utopia. Erwartungsaffekt. Hope.

\section{Introducción: Mann según Lukács, lo burgués y el punto de inflexión}

Voluminosa es sin duda la bibliografía académica que se ha ocupado de la famosa Novelle de Thomas Mann publicada en 1912. La crítica literaria y estética ha vuelto reiteradas veces sobre Der Tod in Venedig a punto tal que se ha incluso compilado su recepción y las distintas tendencias interpretativas constituyen ya un tema en sí mismo. ${ }^{2}$ Mucho menos ha sido dicho, sin embargo, desde la posición marxista que emerge de la interpretación de György

1 Doctora en Filosofía por la Universidad de Buenos Aires e Investigadora del Consejo Nacional de Investigaciones Científicas y Técnicas (CONICET). Se desempeña como docente de grado y posgrado en la Facultad de Filosofía y Letras (UBA). E-mail: mariabelforte@yahoo.com.

2 Como parte de la bibliografía especializada que recopila la recepción de esta novela corta de Mann se pueden destacar, entre otros, el volumen de Ellis Shookman (2003) y el apartado de Francesco Rossi (2015) en el Thomas Mann-Handbuch. 


\section{LA DECADENCIA Y EL AMANECER: UN ANÁLISIS BLOCHIANO...}

María Belforte

Lukács en relación con la tradición burguesa y las imágenes en crisis que Mann plasma en la narración que culmina con la muerte de su protagonista, Gustav Aschenbach. Quien comparte muchos puntos en común con la lectura lukácsiana es Ernst Bloch, que, a pesar de no haber dedicado un estudio específico a la obra, presentó en cambio elementos críticos fecundos para una lectura de la Novelle fundada en su filosofía de la esperanza. Esta lectura resulta heurísticamente valiosa ya que lleva el análisis literario en dirección a derivaciones filosóficas y políticas cuyas implicancias exceden el ámbito estético y vinculan la obra de Mann de 1912 con un paradigma poco frecuentado por tendencias más hegemónicas de la teoría literaria y estética. Se partirá aquí entonces, en primer lugar, de la consideración de Lukács de la obra de Mann para confrontarla luego con una interpretación blochiana de esta Novelle de 1912. El objetivo es mostrar que una interpretación utópica revela aspectos existenciales y estéticos significativos para la crítica.

Hacia mediados de la década del cuarenta, Lukács describe el realismo de Thomas Mann como "Spiegel der Welt" (espejo del mundo) y subraya su representatividad en tanto conciencia de la burguesía alemana (Lukács, 1964, 511). En este caso, se trata, para el filósofo húngaro, del surgimiento de una "forma tan peculiar de representatividad": "Thomas Mann gibt ein vollendetes Bild des Bügerlichen in seiner ganzen Problematik, aber eben das Sein gerade dieses Moments, gerade dieser Etappe” (ibíd., 506). ${ }^{3}$ Cabe señalar que se refiere Lukács aquí a "lo burgués" (das Bürgerlichen) y a una forma especial y peculiar de representación que se orienta en busca de una esencia a partir de su encarnación subjetiva; Mann tendría la convicción, según Lukács, de que "die Frage nach dem wesen des heutigen bürgerlichen Menschen die Frage nach seinem Bürgertum sei. Die Suche nach dem Bürger wirft für ihm alle Fragen der Gegenwart und Zukunft, der Kultur unserer Tage auf' (ibíd., 511). ${ }^{4}$

Tras emprender un camino que se bifurca a partir de este punto, la hipótesis interpretativa que aquí se sostiene llevaría a mostrar que, teniendo en cuenta los análisis teóricos de Ernst Bloch durante la República de Weimar y su trabajo posterior en Das Prinzip Hoffnung, en Der Tod in Venedig es posible encontrar elementos utópicos que señalan más allá de los aspectos decadentes en la obra. Para destacar la presencia de lo utópico en la novela corta de 1912 se contrapondrá la construcción que lleva a cabo Mann entre la intimidad del protagonista,

\footnotetext{
3 "Thomas Mann ofrece una imagen consumada de lo burgués en la plenitud de su problemática, pero, precisamente, su ser mismo de este momento, su ser mismo de esta etapa" (Lukács, 1969, 14).

4 “...la pregunta acerca de la esencia del burgués actual es la pregunta misma acerca de su condición burguesa. En la búsqueda del burgués cobran vida para él todos los problemas, presentes y futuros, de la cultura de nuestro tiempo" (Lukács, 1969, 21).

\begin{tabular}{|c|c|c|c|}
\hline Qevista Dialectus & Ano 10 & n. 21 & Janeiro - Abril 2021 \\
\hline
\end{tabular}
}


asediada por el afectos de la espera (Erwartungsaffekte) negativos, el miedo y la angustia, y el paisaje de la esperanza que rodea su anhelo de juventud en la figura de Tadzio.

Hans Mayer tomó la imagen del punto crítico (Wendepunkt) para analizar el lugar de la literatura de Mann y su significación en la historia alemana (Mayer, 1970, 12s.). Las fechas de 1915, 1924 o 1933 refieren momentos específicos del devenir político y cultural que implicaban una inflexión en los tiempos literarios alemanes. Antes de esta primera fecha, en la que los expresionistas descubrieron el advenimiento de la pasión bélica nacionalista y en la que según Mayer se plasmó la primera desilusión de las vanguardias, Thomas Mann escribe Der Tod in Venedig. Se desvela allí, anticipadamente, un tema central que recorrería la crítica cultural alemana tras la derrota: la presencia de una época de decadencia. Esta idea, plasmada de forma histórico-política regresiva en la popular obra de Oswald Spengler Der Untergang des Abendlandes, posee sus orígenes en las últimas décadas del siglo XIX y se incorpora a la literatura y la cultura alemanas, que retoman el tema de la décadence nietzscheano. ${ }^{5}$ En este sentido, la literatura de Mann, volviendo a los análisis de Mayer, constituiría un hito en relación con lo histórico: "Y es que la descomposición del mundo burgués se hallaba expresada aquí de una forma que supo servirse de la decadencia como concepto ambivalente: descomposición físico-moral y refinamiento espiritual -sensual a la vez-." (ibíd., 22).

Esta interpretación se encuentra en cierta consonancia con la lectura que Lukács le dedica en distintos ensayos y que se sostiene sobre el concepto de "realismo crítico". El tema central de su literatura, sostiene el filósofo húngaro, es la búsqueda del auténtico sujeto burgués. Lukács explica entonces la crítica humanista de Mann como una respuesta a la decadencia del ideal burgués, desde una perspectiva burguesa. Pero esta perspectiva lleva a Lukács a negar la presencia de todo elemento utópico en la literatura manniana. ${ }^{6}$ Es en este punto en donde la interpretación de Bloch se encamina en una dirección alejada de su amigo húngaro y que puede plantearse como una continuación o un paso más en el análisis crítico- marxista del escritor alemán. ${ }^{7}$

5 Como sostiene Dieter Borchmeyer, el término posee en Nietzsche no solamente la tradicional connotación negativa, sino también un vínculo con la transmutación positiva de los valores. En Nietzsche, se trata asimismo de "una etapa de tránsito en el proceso de evolución de la vida" (Borchmeyer, 2012, 139).

6 Lukács sostiene esta idea en reiteradas oportunidades, basta citar el comienzo de su ensayo "Auf der Suche nach dem Bürger": "Die Frage wird noch komplizierter, weil dem Schaffen (freilich nicht immer dem Denken) Thomas Manns jeder utopische Zug fehlt” (Lukács, 1964, 505) (“La pregunta aún se complica más si se advierte que a la obra de Thomas Mann (aún cuando, por supuesto, no siempre a su pensamiento) le falta todo rasgo utópico") (Lukács, 1969, 13).

7 No es objetivo del presente artículo una confrontación con la obra de Lukács ni con su interpretación de Mann, sino que se toma esta como punto de partida para la introducción de una lectura blochiana, aún menos extendida en la crítica literaria. En este sentido, aunque no es este el lugar indicado, podrían recuperarse los indicios de 


\section{LA DECADENCIA Y EL AMANECER: UN ANÁLISIS BLOCHIANO...}

María Belforte

Se propone aquí entonces reconstruir una lectura de Der Tod in Venedig a partir de conceptos blochianos que discuten la negación de lo utópico en la Novelle. Para ello se retomará, en primer lugar, la idea de juventud en Bloch y a continuación se estudiarán los análisis y clasificaciones de los conceptos de Erwartungsaffekt y de esperanza en Bloch para finalmente interpretar la obra de Mann de 1912 a la luz de estas nociones. El objetivo es mostrar la resignificación de la idea de muerte en la Novelle y las consecuencias existenciales que de esta lectura se desprenden.

\section{La juventud como estado del ser humano}

La juventud como motivo de época constituye una marca propia de la cultura alemana de preguerra. Desde el Jugendstil hasta la presencia social política de la Jugendbewegung, que marca una tendencia desde finales del siglo XIX, el tema aglutina una serie de elementos específicos y se vincula con otros más generales que dominan las expresiones de la literatura, el arte y la política. Si a un nivel supraindividual los procesos históricos mostraban un desenvolvimiento que pondría en escena la idea de "decadencia", la contracara subjetiva sería la exaltación del "hombre nuevo", fuertemente ligado a la noción de comienzo y de juventud.

Como parte de su filosofía de la utopía, Ernst Bloch colocó a la juventud en un lugar destacado de sus reflexiones filosóficas y políticas. Entre las distintas vertientes que dan origen a esta centralidad se destaca un horizonte histórico: la rebelión generacional contra la cultura de la burguesía imperial llega en la Alemania guillermina a tomar la forma de un movimiento que Bloch conoció de cerca. Ya tempranamente en sus escritos, el filósofo discrimina entre la juventud no proletaria "tonta" y "bruta" (dumm, roh) (Bloch, 1985, 11) y otro sentido de la juventud, de carácter metafísico, identificado con la música y cercano al núcleo de su filosofía temprana y a la implementación que allí posee el concepto central de utopía. ${ }^{8}$ Pero Bloch señalará que, centrado en la actitud contemplativa, en la que lo pasado monopoliza el presente e inhibe el aprendizaje de lo aún no consciente, el hombre no ha aprendido aún a conocer el

cierta afinidad entre los filósofos en relación a lo utópico en la literatura burguesa. En su ensayo Franz Kafka oder Thomas Mann?, Lukács sostiene la presencia de una perspectiva utópica después de la Revolución Francesa y, según esta posición, incluso en la etapa posterior del realismo crítico, en la que se renuncia resignadamente a la esperanza utópica, "Soweit in dieser Welt noch Utopien entstehen, nehmen sie die Form einer Flucht ins räumlich und zeitlich Ferne, ins Exotische auf” (Lukács, 1971, 517) ("Si en este mundo todavía surgen utopías, adquieren la forma de una huida a lo lejano en el espacio y en el tiempo: al exotismo") (Lukács, 1984, 78-79).

8 Las dos versiones de Geist der Utopie comienzan con el objetivo de plantear un comienzo, cfr. Bloch, $1985,11$. 
afecto que lo vuelca hacia lo que denomina el Novum. Este concepto blochiano se diferencia del concepto corriente de lo nuevo, entendido como la no repetición del pasado. Bloch, interpreta lo nuevo, lo que él denomina el Novum, como una actualización a partir de la totalidad histórica, con su propia identidad específica y temporal (Siebers, 2012, 414). En este sentido, lo auténticamente nuevo en la historia (por ejemplo, los nuevos modelos de conducta, las revoluciones) es posible “a contraluz de las utopías” (íd.). El elemento fundamental es aquí, no una iteración que produce diferencia, sino una repetición, "la repetición de lo que aún no existe" (íd.). ${ }^{9}$ Aunque el tema de la juventud, como elemento determinante de la pregunta por la subjetividad se encuentra anclado al problema del nosotros, desde el punto de vista de la vida humana singular, la juventud muestra una especial evidencia del crepúsculo hacia adelante, de lo aún-no, de lo utópico. Se trata de un estado o condición (Zustand) del ser humano que lo predispone a lo nuevo y por ello lo abre a la latencia de lo aún no acontecido. No se trata en ese sentido, de un estado cronológico de la vida, sino existencial. En Das Prinzip Hoffnung, juventud es sinónimo de "movimiento hacia adelante" (Bewegung nach vorwärts) ${ }^{10}$ (Bloch, 1993, 133) y la vejez en la sociedad burguesa puede caer en un sentimiento de sufrimiento y opresión (Bloch 1993, 40s.): “zum bloßen Leiden am Alter, sofern es nur einigermaßen ein gesundes ist, aufgebaut auf einem tüchtigen Leben, gehören ein Tropf, der es erfährt, und eine spätbürgerliche Gesellschaft, die sich verzweifelt auf Jugend schminkt” (ibíd., 40). ${ }^{11}$

La construcción del personaje de Tadzio en Der Tod in Venedig se funda en elementos constitutivos de este sentido de la juventud como condición o estado de apertura y posibilidad, lo que la vuelve contraimagen del protagonista, temeroso, decadente y maduro. ${ }^{12}$ La idealización de la juventud unida a la belleza se opone en Aschenbach a la realidad de una vejez a la espera de ser anulada. ${ }^{13}$ En este sentido, se muestra una profundidad mayor del

9 La trad. es mía.

10 Bloch tiene claro, sin embargo, en qué medida la Jugendbewegung constituyó una forma de "bürgerlische Gruppenutopie": "Es ist der Wandervogel nicht nur eine deutsche, sondern vor allem eine kleinbürgerlische Erscheinung, von daher das klassenmäßig wie inhaltlich Verwehte seines Traums" (Bloch, 1993, 684) ("El Wandervogel no es solo un fenómeno alemán, sino, sobre todo, un fenómeno pequeño-burgués, de donde procede el elemento clasista y el contenido vagoroso de su sueño") (Bloch, 2006, 160).

11 "para el mero sufrimiento por la vejez, siempre que ésta sea, en cierto modo, sana y se alce sobre una vida de trabajo, son necesarios un necio como sujeto y una sociedad burguesa tardía que quiere vestirse desesperadamente de juventud" (Bloch, 2007, 65).

12 Que la juventud es un elemento determinante en el anhelo del protagonista es evidente en distintos pasajes de la obra, por ejemplo, de manera explícita en el intento de rejuvenecer por medio de elementos cosméticos: "[Aschenbach] erblickte mit Herzklopfen einen blühenden Jüngling” (Mann, 1960, 519) ("[Aschenbach] vio, y el corazón le dio un vuelco, a un joven floreciente" (Mann, 1999, 109-110).

13 La autopercepción de la falta de juventud en Aschenbach destruye momentáneamente su estado afectivo positivo: "der Anblick seines grauen Haares, seiner scharfen Gesichtszüge stürzte ihn in Scham und Hoffnungslosigkeit" (Mann, 1960, 518) ("la visión de sus cabellos grises y los perfilados rasgos de su rostro lo sumía en la vergüenza y la desesperanza”) (Mann, 1999, 108).

\begin{tabular}{|l|l|l|l|l|}
\hline Q Povista Q Dialectus & Ano 10 & n. 21 & Janeiro - Abril 2021 & p. $97-115$ \\
\hline
\end{tabular}


contenido de la espera frente al de lo representado, característica propia de los Erwartungsaffekte.

\section{Los afectos en la filosofía de Ernst Bloch: análisis y clasificación}

El cuento maravilloso de los hermanos Grimm que lleva por título "Märchen von einem, der auszog das Fürchten zu lernen”, constituye la referencia literaria de la que parte la obra de Bloch Das Prinzip Hoffnung. Pero emprender un viaje para aprender qué es el miedo parece una idea absurda para la subjetividad de la segunda posguerra del siglo XX; Das Prinzip Hoffnung propone, por el contrario, el camino opuesto al del cuento sobre Hans, el de un traspasar para aprender no qué es el temor, afecto de la espera aprendido y vivenciado ampliamente por la humanidad, sino el derrotero analítico de pensar el afecto de la espera positivo más humano y desconocido: la esperanza. Para ello, la obra no solamente vuelve analíticamente sobre conceptos centrales de la filosofía occidental, sino que trabaja a contrapelo de las imágenes utópicas de la literatura, el arte y la cultura para rescatar los elementos desperdigados de lo nuevo y "salvarlos" de su disolución en el discurso hegemónico de la historia.

Desde las primeras páginas de Das Prinzip Hoffnung, Bloch subraya la relevancia de la subjetividad como comienzo de su análisis filosófico: "Wer sind wir? Wo kommen wir her? Wohin gehen wir? Was erwarten wir? Was erwartet uns?” (Bloch, 1993, 1). ${ }^{14}$ Este planteo va a distinguir ya en la segunda parte, dos tipos de estados de la conciencia: aquellos pensamientos determinados por el objeto, frente a aquellos otros, que interesan especialmente a Bloch, cuyos actos intencionales son los únicos dados en presente, es decir, aquellos que son primariamente estados en sí mismos y que constituyen las intenciones más activas: los afectos (Affekte). ${ }^{15}$ En tanto incluida dentro de los modos del ser intencional, la naturaleza de la intencionalidad de los afectos es una intencionalidad tal que tiene lugar en sí misma, volcada casi inmediatamente a sí misma: "die Affekte selber sind als Intentionsakte sich zuständlich

14 “Quién somos? ¿De dónde venimos? ¿Adónde vamos? ¿Qué esperamos? ¿Qué nos espera?” (Bloch, 2007, 25).

15 Bloch diferencia el afecto de la sensación (Empfindung) y la representación (Vorstellung): “Also unterscheiden sich Affekte von Empfindungen, Vorstellungen nicht zuletzt dadurch, daß sie vor sich gehen, indem sie ihres Vorgangs als eines doch noch halb unmittelbaren Selbstgefühls nahe innewerden" (Bloch, 1993, 77) ("Los afectos se diferencian por eso, y no en último término, de las sensaciones y de las representaciones en que tienen lugar ante sí, de tal manera que se percatan de su proceso como si se tratara de un sentimiento casi inmediato de sí mismo") (Bloch, 2007, 99).

\begin{tabular}{|l|l|l|l|l|}
\hline Q $R$ ovista Qialectus & Ano 10 & n. 21 & Janeiro - Abril 2021 & p. $97-115$ \\
\hline
\end{tabular}


gegeben” (Bloch, 1993, 78s.). ${ }^{16}$ Son estados en sí mismos, y en su percepción según el contexto, los afectos pueden aparecer antes de que surja un objeto externo con el que se relaciona el ánimo ${ }^{17}$. La contraprueba de esta relación especial de los afectos con el objeto exterior se constata en la tradición del pensamiento determinado por el objeto: "Wobei die Gegenprobe sein mag, daß das gesamte objekthafte Denken von den Affekten, als einem Erkenntnisorgan, sich notwendig abkehrt" (ibíd., 80). ${ }^{18}$

Para Bloch, en cambio, los afectos no se restringen al "puro vivenciar de sus vivencias" (das bloße Erleben ihres Erlebnisses) (ibíd., 78) y constituyen una clave para la comprensión de lo humano debido a que son formas de la intención que presentan la forma más activa. Bloch rechaza los intentos de clasificación externos a una teoría de los afectos: "das von außen an die Affektenlehre Herangebrachte muß gänzlich beseitigt werden" ${ }^{19}$ y propone diferenciarlos en "afectos llenos o saturados" (gefüllte Affekte), para los cuales el objeto se encuentra accesible al individuo, en el mundo ya a la mano (in der bereits zurhandenen Welt), por ejemplo la envidia, la codicia o el respeto (ibíd., 82) y afectos de la espera (Erwartungsaffekte), de los que puede dudarse el resultado debido a que el objeto no se halla a disposición. En todos los casos, "[d]ie Intention in allem Erwartungsaffekten ist eine vorausweisende, die Zeitumgebung ihres Inhalts ist Zukunft" ${ }^{\prime 20}$ (Bloch, 1993, 122). Una característica que los diferencia de los saturados es "su orientación intencional fuertemente anticipatoria" (íd.). Para Bloch, los gefüllte Affekte implican una forma de futuro inauténtico, en el que no ha ocurrido nada nuevo. Estos intencionan un futuro representable, que no contiene nada objetivamente nuevo (íd.). En este punto, cita a Husserl para el cual erróneamente, según Bloch, todos los afectos, no solamente los saturados, se encuentran en el horizonte de las representaciones del recuerdo, Husserl sostiene: “'Jeder ursprünglich konstituierende Prozeß

16 "los afectos están dados ellos mismos en presente como actos intencionales" (Bloch, 2007, 100).

17 Bloch realiza una crítica a la tradición filosófica idealista mediante la introducción del concepto de ánimo (Gemüt) en sus análisis: 'nur das 'Gemüt', als Inbegriff der Gemütsbewegungen, ist ein 'existentieller' Begriff, einer der 'Betroffenheit' geworden, nicht der theoretisch-objektive 'Geist"” (Bloch, 1993, 79) ("sólo el ‘ánimo', como conjunto de los movimientos del ánimo, es un concepto 'existencial', un concepto de la 'afección', no del concepto teórico objetivo del 'espíritu”’) (Bloch, 2007, 101).

18 "Y la prueba en sentido contrario puede ser que todo el pensamiento determinado por el objeto vuelve necesariamente las espaldas a los afectos como órgano del conocimiento." (Bloch, 2007, 101).

19 "es preciso eliminar totalmente los criterios traídos desde fuera a la teoría de los afectos" (Bloch, 2007, 104). Bloch argumenta en este punto que: "Von außen her wurden die Triebgefühle stets nur unzulänglich geordnet und eingeteilt" (Bloch, 1993, 81) ("Desde fuera, los sentimientos de los impulsos sólo han sido ordenados y clasificados siempre de modo insuficiente") (Bloch, 2007, 102).

20 "La intención en todos los afectos de la espera señala hacia adelante, la temporalidad de su contenido es futuro" (Bloch, 2007, 141).

\begin{tabular}{|c|c|c|c|c|}
\hline Q & Ano 10 & n. 21 & Janeiro - Abril 2021 & p. $97-115$ \\
\hline
\end{tabular}


ist beseelt von Protentionen, die das Kommende als solches leer konstituieren und auffangen",21 (íd.). Pero, para Bloch, esto implica desconocer la especial condición de los afectos de la espera: “Jedoch diese 'Protentionen' haben in der Erinnerung und den von ihr 'fundierten' Affekten das Ihre bereits empfangen, sie haben nur einen 'auf die Zukunft des Wiedererinnerten gerichteten Horizont', der, mit seiner unechten Zukunft, eben 'gesetzter Horizont' ist"22 (ibíd., 122s.).

En cambio, en los afectos de la espera, que se refieren a algo exterior, el contenido de la espera muestra mayor profundidad que el contenido de la representación dado: "der Erwartungsinhalt zeigt eine größere 'Tiefe' als der jeweils gegebene Vorstellungsinhalt"23 (ibíd., 122). Los afectos de la espera se fundamentan en algo que no existe, por ejemplo, explica Bloch, “jede Hoffnung impliziert das höchste Gut, hereinbrechende Seligkeit, die so noch nicht da war"24 (íd.); en este sentido, se refieren al futuro en sentido auténtico.

Bloch subdivide los afectos de la espera a su vez en dos categorías, afectos de la espera negativos y positivos. Dentro de los primeros incluye aquí a la angustia (Angst), el miedo (Furcht), el susto (Schreck) y como caso extremo, la desesperación (Verzweiflung). Dentro de los positivos, a la esperanza (Hoffnung) y la confianza (Zuversicht) (ibíd., 121). Le reconoce entonces a Heidegger el lugar central que este le otorga a los afectos en su construcción filosófica que rompe definitivamente con la corriente hegemónica del pensamiento determinado por el objeto. Pero a partir de allí elabora una acérrima crítica al lugar que este le otorga a la angustia, al convertirla en "sein eigenstes In-der-Welt-Sein" (su auténtico ser en el mundo). El autor de Sein und Zeit, sostiene Bloch, al hacer de la angustia "die existentielle 'Grundbefindlichkeit"'25, aísla subjetivamente al hombre (ibíd., 123s.). Bloch articula su crítica a los afectos en Heidegger a partir de la indiferenciación que en este poseen los conceptos de Befindlichkeit (disposicionalidad) y Stimmung (estado de ánimo). Escribe:

Es bleiben Befinden und Stimmung hier ungetrennt; so hindert die Flachheit in diesem ungeschieden animalischen Gewoge jede Ahnung vom Dunkel des wirklich unmittelbaren Existere [...]. [...] Hier also fällt aus der Stimmung, indem sie einzig

21 “'Todo proceso originariamente constituyente está animado por 'protenciones', que constituyen y aprehenden vacío lo porvenir como tal"” (Bloch, 2007, 142).

22 "Sin embargo, estas 'protenciones' han recibido ya lo suyo propio en el recuerdo y en los afectos 'fundados' por él, y sólo poseen un 'horizonte dirigido al futuro del recordar de nuevo', el cual, con su futuro inauténtico, es precisamente 'horizonte puesto"” (Bloch 2007, 142).

23 "el contenido de la espera muestra una 'profundidad' mayor que el contenido de la representación del momento" (Bloch, 2007, 142).

24 “toda esperanza implica el bien supremo, la irrupción de la bienaventuranza, que, así, no existe" (Bloch 2007, 142).

25 “el 'encontrarse fundamental' existencial” (Bloch, 2007, 143).

\begin{tabular}{|l|l|l|l|l|}
\hline Rovista 2 ilalectus & Ano 10 & n. 21 & Janeiro - Abril 2021 & p. $97-115$ \\
\hline
\end{tabular}


als eine von erlöschendem Leben, das ist hier: von niedergehender Klasse sich kundgibt, völlig der Wunschcharakter aus, ohne den doch auch diese Diffusheit von Affekten, als eine von Affekten, nicht bestehen kann (ibíd., 118s.). ${ }^{26}$

Al confundir Befindlichkeit, concepto que Bloch vincula con los estados corporales y con la percepción que el cuerpo tiene de sí mismo, con Stimmung, Heidegger pasa por alto el elemento determinante del yo ligado a los afectos y a los sueños diurnos (Tagträumen). Con la desaparición del componente desiderativo en el estado de ánimo, Heidegger hunde existencialmente al hombre en el nihilismo y lo prepara para una fenomenología pequeñoburguesa y animal de la experiencia. ${ }^{27}$ Para Bloch, este estado de ánimo centrado en el aburrimiento de la cotidianeidad se encuentra unido de modo esencial "a la empresa capitalistamecanizada" (ibíd., 119). Su concepción de Stimmung, en cambio, implica la posibilidad de un cambio repentino, exige distensión en el sentido de salida o fuga (Ausreisen) -no de adormecimiento- y constituye el medium de los sueños diurnos.

\section{Aprender la esperanza: un contraconcepto de la angustia en Der Tod in Venedig}

Frente a la centralidad de la angustia en la filosofía heideggeriana, Bloch funda su obra en el afecto de la espera positivo de la esperanza y lo concibe como, por un lado un contraconcepto (Gegenbegriff) de la angustia (Angst) pero también del recuerdo (Erinnerung) (Bloch, 1993, 126). Con ello se distancia de la caracterización husserliana de los afectos como formas de la intencionalidad cuyas protenciones encuentran fundamento en el recuerdo, y de esta manera, subraya su estado de apertura. Pero, al otorgarle Bloch una especial consideración a la esperanza, la diferencia de los demás afectos por su capacidad de "rectificación lógicoconcreta y agudización” (íd.). Esto implica un componente especial que la convierte en un

26 'La 'disposición afectiva' y el 'estado de ánimo' quedan aquí indiferenciados; y así la superficialidad en esta onda animal indiferenciada impide todo vislumbre de la oscuridad del verdadero y directo existere [...]. [...] $\mathrm{Al}$ entender así el estado de ánimo como algo propio de una vida agonizante o, lo que es lo mismo aquí, de una clase que camina a su ocaso, el estado de ánimo pierde completamente el carácter desiderativo, sin el cual tampoco esta difusión de afectos puede subsistir como constituida por afectos..." (Bloch, 2007, 138-139).

${ }^{27}$ Cabe aplicar según Bloch en este caso la crítica a la subjetividad individualista de la clase burguesa: "Und nicht der ganzen Menschheit Jammer, sondern einzig der des unerhellt-hoffnungslosen Kleinbürgertums faßt einen an, kommt es bei Heidegger, was die 'Abgründe' solcher Befindlichkeit angeht, zu diesem Satz: 'Die tiefe Langeweile, in den Abgründen des Daseins wie ein schweigender Nebel hin und her ziehend, rückt alle Dinge, Menschen und einen selbst mit ihnen in eine merkwürdige Gleichgültigkeit zusammen. Diese Langeweile offenbart das Seiende im Ganzen"” (Bloch, 1993, 119) ("Y no el dolor de toda la humanidad, sino sólo el de la desesperada y ciega pequeña burguesía, se apodera de uno, y lleva a Heidegger, por lo que se refiere a los 'abismos' de este encontrarse, a las siguientes palabras: 'El profundo aburrimiento, que discurre aquí y allá como una niebla errática en los abismos del Dasein, reúne a todas las cosas y todos los hombres y a uno mismo con ellos en una extraña indiferencia. Este aburrimiento revela al ente en el todo"') (Bloch, 2007, 138-139).

\begin{tabular}{|l|l|l|l|l|}
\hline Ronista Dialectus & Ano 10 & n. 21 & Janeiro - Abril 2021 & p. $97-115$ \\
\hline
\end{tabular}


afecto único: el proceso cognoscitivo que le resulta inherente. Y de allí deriva Bloch el fuerte carácter práctico y militante de la esperanza.

Es de especial atención, para el análisis aquí propuesto, la relación que Bloch establece entre la esperanza y la muerte. A partir de un verso del poema "Patmos", de Hölderlin, "Wo Gefahr ist, wächst das Rettende auch", Bloch afirma que "hay todavía salvación... en el horizonte", y establece un momento decisivo (Wendemoment) "dialéctico-positivo" en el que es posible la desaparición del miedo al momento de la muerte (Todestelle). Así sostiene finalmente "die Hoffnung ersäuft die Angst"28 (ibíd., 126). Un pasaje resume la esencialidad del concepto para la subjetividad:

\footnotetext{
Hoffnung, dieser Erwartungs-Gegenaffekt gegen Angst und Furcht, ist deshalb die menschliste aller Gemütsbewegungen und nur Menschen zugänglich, sie ist zugleich auf den weitesten und den hellsten Horizont bezogen. Sie steht jenem Appetitus im Gemüt, den das Subjekt nicht nur hat, sondern aus dem es, als unerfülltes, noch wesentlich besteht (ibíd., 83s.). ${ }^{29}$
}

Si desde una lectura marxista, Der Tod in Venedig ha sido interpretada como una obra del realismo burgués ajena a la presencia de lo utópico, la filosofía de Bloch y su interpretación de cierto pasaje pueden poner en cuestión este estado de cosas de la crítica. Según un ensayo de Lukács de 1945, el destino de Mann fue nacer “en la época de la decadencia” (Lukács, 1964, 519). Su literatura poseería en consecuencia, de acuerdo con Lukács, un "pathos" peculiar que implicaría el intento de superar esta decadencia en sus últimas consecuencias morales por medio de lo que denomina "ein gestalterisches Auf-die-Spitze-Treiben” (íd.). La coyuntura de la Gran Guerra incitó a Mann y a la burguesía de su época a exponer lo que Lukács expresa con la construcción nominal "machtgeschützte Innerlichkeit" hasta convertirse ella misma en resguardo ideológico de ese poder, es decir del imperialismo prusiano (íd.). ${ }^{30}$ En un ensayo de 1943, en el que Lukács se refiere específicamente al personaje de la Novelle para un análisis del prusianismo, también utiliza el concepto de "actitud" (Haltung), para su estudio del comportamiento del protagonista:

28 "la esperanza anega la angustia" (Bloch, 2007, 146).

29 "La esperanza, este anti-afecto de la espera frente al miedo y el temor, es, por eso, el más humano de todos los movimientos del ánimo y sólo accesible a los hombres, y está, a la vez, referido al más amplio y al más lúcido de los horizontes. La esperanza se corresponde a aquel apetito en el ánimo que el sujeto no sólo posee, sino en el que él consiste esencialmente, como ser insatisfecho" (Bloch, 2007, 105).

30 Luego, sostiene Lukács, la lucha por la democracia será en Mann una expresión de esa lucha contra la decadencia (Lukács, 1964, 521).

\begin{tabular}{|c|l|l|l|l|}
\hline Govista Dialectus & Ano 10 & n. 21 & Janeiro - Abril 2021 & p. $97-115$ \\
\hline
\end{tabular}




\begin{abstract}
Die „Haltung" ist "etwas rein Formelles und bietet für die Lebensführung, wenn sich nur einigermaßen ernste Abgründe auftun, nicht den geringsten Halt. Als der Held der Novelle vor einem inneren Konflikt steht, genügt ein Traum, seine ganze „Haltunge“, seine ganze mühsam zusammenkonstruierte Lebensführung schmählich zusammenbrechen, die mühsam gebändigte seelische Unterwelt der Instinkte vollständige Herrschaft über ihn gewinnen zu lassen. Thomas Mann gestaltet hier mit tiefem psychologischem Einblick die gefährliche seelische Hohlheit der preußischen „Haltung": gerade dadurch, daß jeder moralische Wertakzent auf die „Haltung" fällt und die Subjektivität des Instinktlebens bloß als zu bändigendes Material behandelt wird, ist in ruhigen Zeiten die scheinbare Macht des formal geregelten Lebens eine grenzenlose; ihre wirkliche Durchdringung der Gesamtpsyche ist aber so geringfügig, daß sie beim ersten Ansturm, vollständig versagt (Lukács, 1948, 86). ${ }^{31}$
\end{abstract}

El enfoque de Lukács es aquí histórico-crítico y le permite mostrar cómo las formas sociales se relacionan con lo que denomina "Instinktleben". Este concepto se contrapone a la idea de "Haltung" (actitud), que pretende ser "férrea" pero que, según Lukács, tan solo es "rígida" y por lo tanto "se quiebra" (brechen) súbitamente. Se percibe aquí cómo Lukács analiza la subjetividad por medio de una dinámica naturaleza-forma, correspondiéndose esta última a la regulación de orden histórico-social. ${ }^{32}$ Queda sin tratar en este análisis la condición ontológica de esa "vida instintiva" en tanto complejo de elementos constitutivos o existenciales del ser humano. Por eso es que en su lectura, lo que quiebra la conducta de Aschenbach no es estudiado en detalle: "Jedoch nur ein kleiner Konflikt ist vonnöten, ein Traum inmitten dieses Konflikts, für dessen Enstscheidung noch kaum etwas Wahrnehmbares geschah - und die ,Haltung' bricht rettungslos und widerstandslos zusammen, als ob sie nicht das Produkt eines ehrlichen asketisch schwer durchfochtenen Lebens gewesen wäre” (Lukács, 1964, 515). ${ }^{33}$ Lukács interpreta el

31 'La 'actitud' es algo puramente formal y no ofrece el menor sustento para el régimen de vida, cuando se abren abismos, en alguna medida, serios. Cuando el héroe de la novela corta se encuentra ante un conflicto interno, basta un sueño para quebrar indecorosamente toda su 'actitud', todo su régimen de vida arduamente pergeñado, para dejar que el submundo anímico de los instintos laboriosamente domado adquiera un dominio completo sobre él. Thomas Mann configura aquí, con una profunda comprensión psicológica, la peligrosa vacuidad anímica de la 'actitud' prusiana: precisamente porque todo acento valorativo moral cae sobre la 'actitud' y la subjetividad de la vida instintiva es tratada meramente como material a ser dominado; el poder aparente de la vida regulada formalmente es, en épocas tranquilas, ilimitado; pero su verdadera penetración de la psique íntegra es tan insignificante que, a la primera embestida, colapsa completamente.” (Lukács, 2019, 166). La misma idea respecto de la "actitud" de Aschenbach aparece en el ensayo "Auf der Suche nach dem Bürger", allí sostiene que "Er [Aschenbach] hat ein formvollendetes Leben und ein gewichtiges Werk auf der Grundlage der «Haltungs»-Moral aufgebaut”, cfr. Lukács, 1964, 513ss.; aquí, 515. (“'Aschenbach] ha construido una vida formalmente perfecta y una obra importante basándose en la moral de la 'actitud"') (Lukács, 1969, 26, la trad. ha sido modificada).

32 Podría observarse que el abordaje de Lukács en este contexto posee una perspectiva diferente de la que puede encontrarse en los escritos de la Ontología. Allí, estudia la subjetividad con categorías que posiblemente se corresponden en mayor medida con las propuestas por Bloch en Das Prinzip Hoffnung. Resulta evidente que un trabajo comparativo sobre este punto supera ampliamente la dimensión del presente artículo.

33 "Un pequeño conflicto, tiene sólo lugar, sin embargo, un sueño en medio de este conflicto, para cuya decisión apenas ocurrió nada perceptible, -y la 'actitud' se derrumba sin resistencia ni salvación posible, como si no fuera el producto de una vida difícilmente construida a base de sinceridad y ascetismo" (Lukács, 1969, 26, la trad. ha sido modificada).

\begin{tabular}{|l|l|l|l|l|}
\hline Q ovista Q7ialectus & Ano 10 & n. 21 & Janeiro - Abril 2021 & p. $97-115$ \\
\hline
\end{tabular}


pathos del protagonista mediante el análisis de lo que denomina un "Dilemma" en Mann: la contraposición entre la "anarquía del sentimiento" (Gefühlsanarchie) y la "actitud" (Haltung). ${ }^{34}$ La categoría central aquí para el análisis de Aschenbach es una noción del orden social, vinculada a un proceso histórico, con una lógica subyacente, a la que contrapone otra, vinculada a la interioridad, que es condenada al ámbito de la anarquía y dejada de lado en el proceso de análisis crítico. El sentimiento en Bloch en cambio - y utiliza él para ello el concepto de Affekt o Triebgefühl- es objeto de análisis detallado.

En este punto, el análisis blochiano de los sentimientos da entonces un paso más: al detenerse en la diferenciación entre Stimmung y Befindlichkeit, se plantea un examen de la constitución anímica de esa "vida instintiva", de la "anarquía del sentimiento" para recuperar los aspectos afectivos de la interioridad de la existencia y analizar su contenido. Por ello, considera el sentimiento instintivo (Triebgefühl), que no es solamente disposición, siempre dirigido a algo exterior, lo que le permite a Bloch mostrar las consecuencias prácticas y cognitivas de esta interioridad.

La representación artística de aquello que Lukács llama "machtgeschützte Innerlichkeit" implica la plasmación del contenido utópico de la Stimmung que posee en sí misma momentos azules y no solamente oscuros e indiferenciados. De allí que Bloch explícitamente, y aquí habría una distancia respecto de su amigo de juventud, reconozca en esta obra de Mann la plasmación del estado de ánimo ascendente en el que se apoya la esperanza. En el reflejo del paisaje de la alborada frente al protagonista, Mann, de acuerdo con esta lectura de Bloch, describe "das unsäglich holde Blühen der Morgenröte mit all ihrem fernherscheinenden Arpeggio ante lucem" (Bloch, 1993, 126). ${ }^{35} \mathrm{El}$ pasaje al que se refiere Bloch ilumina la relación entre el paisaje y el afecto de la espera positivo:

\begin{abstract}
Aber ums erste Morgengrauen weckte ihn ein zart durchdringendes Erschrecken, sein Herz erinnerte sich seines Abenteuers, es litt ihn nicht mehr in den Kissen, er erhob sich, und leicht eingehüllt gegen die Schauer der Frühe setzte er sich ans offene Fenster, den Aufgang der Sonne zu erwarten. Das wundervolle Ereignis erfüllte seine vom Schlafe geweihte Seele mit Andacht. Noch lagen Himmel, Erde, und Meer in geisterhaft glasiger Dämmerblässe; noch schwamm ein vergehender Stern im Wesenlosen. Aber ein Wehen kam, eine beschwingte Kunde von unnahbaren Wohnplätzen, daß Eos sich von der Seite des Gatten erhebe, und jenes erste, süße Erröten der fernsten Himmels- und Meeresstriche geschah, durch welches das Sinnlichwerden der Schöpfung sich anzeigt. [...] Angestrahlt von der Pracht des Gottes saß der Einsam-Wache, er schloß die Augen und ließ von der Glorie seine
\end{abstract}

\footnotetext{
${ }^{34}$ El análisis de Lukács excede Der Tod in Venedig ya que se dirige a mostrar la búsqueda del burgués en distintos personajes de la obra de Mann. De allí que este dilema se plantee también, por ejemplo, para el examen de la figura de Thomas Buddenbrook (Lukács, 1964, 512ss.).

35 "la aparición indeciblemente hermosa de la aurora con todo su lejano arpegio ante lucem" (Bloch, 2007, 145). 
Lider küssen. Ehemalige Gefühle, frühe, köstliche Drangsale des Herzens, die im strengen Dienst seines Lebens erstorben waren und nun so sonderbar gewaldelt zurückkehrten, - er erkannte sie mit verwirrtem, verwundertem Lächeln (Mann, 1960, 495)..$^{36}$

A partir de esta referencia, y de la filosofía de los afectos blochiana, Der Tod in Venedig puede interpretarse como una forma estética que plasma la aparición de un afecto de la espera positivo en el contexto de la decadencia burguesa. La obstinación de Aschenbach en permanecer junto a Tadzio puede explicarse recurriendo a estos elementos del análisis de Bloch y, en este sentido, sería el afecto de la esperanza del personaje el que se mantendría dominante a lo largo de la Novelle.

Distintos elementos de la obra indican en esta dirección. Por un lado, la necesidad del viaje emprendido por Aschenbach se le revela al protagonista en medio de un pasaje del temor a la esperanza (temor a permanecer en el campo y a las figuras cotidianas de ese entorno $^{37}$; deseo de viajar que surge como un ataque ${ }^{38}$ ). La descripción de este afecto en Mann se lleva a cabo con la referencia explícita a la razón y lazo determinante de la praxis que define a la espera positiva: "Auch wurde denn, was ihn da eben so spät und plötzlich angewandelt, sehr bald durch Vernunft und von jung auf geübte Selbstzucht gemäßigt und richtiggestellt" (Mann, 1960, 448). ${ }^{39}$

Por otro lado, Mann describe de manera acabada la Stimmung del personaje y muestra la fugacidad e inestabilidad que esta posee de acuerdo con el análisis de Bloch. Bloch

36 "Un tierno escalofrío de temor lo despertaba con las primeras luces del alba; su corazón recordaba su aventura, y él, no pudiendo soportar por más tiempo las sábanas, se levantaba y, ligeramente cubierto para protegerse del fresco matutino, se sentaba junto a la ventana abierta a esperar la salida del sol. El prodigioso espectáculo infundía recogimiento a su alma consagrada por el sueño. Cielo, tierra y mar yacían aún inmersos en una lividez crepuscular, espectral, hialina; en la infinitud flotaba todavía alguna estrella moribunda. Pero, de pronto, una brisa, un alado mensaje proveniente de inaccesibles moradas venía a anunciar que Eos había abandonado el lecho de su esposo; y en las zonas más remotas del cielo y del mar aparecía aquel dulce resplandor primero, cuya rubicundez anuncia el renacer del universo para los sentidos. [...] Irradiado por el resplandor del dios, el solitario vigilante cerraba los ojos dejando que la majestad divina besara sus párpados. Con una sonrisa entre confusa y admirada reconocía entonces antiguos sentimientos, penas del corazón tempranas y entrañables que, asfixiadas por el severo oficio de toda una vida, retornaban ahora, extrañamente transformadas" (Mann, 1999, 79-80).

37 "Er fürchtete sich vor dem Sommer auf dem Lande, allein in dem kleinen Hause mit der Magd, die ihm das Essen bereitete, und dem Diener, der es ihm auftrug; fürchtete sich vor den vertrauten Angesichten der Berggipfel und -wände, die wiederum seine unzufriedene Langsamkeit umstehen würden. [...] Reisen also er war es zufrieden” (Mann, 1960, 449) (“Temía el verano en el campo, la soledad en esa casita compartida con una criada que le preparaba la comida y un mayordomo que se la servía; temía el rostro familiar de las montañas, cuyas cumbres y laderas circundarían de nuevo su insatisfecha morosidad. [...] Viajar, sí... aceptaba la idea") (Mann, 1999, 21).

38 "Es war Reiselust, nichts weiter; aber wahrhaft als Anfall auftretend und ins Leidenschaftliche, jab is zur Sinnestäuschung gesteigert” (Mann, 1960, 446s.) ("Eran ganas de viajar, nada más; pero sentidas con una vehemencia que las potenciaba hasta el ámbito de lo pasional y alucinatorio") (Mann, 1999, 18).

39 “Además, aquel capricho que tan tardía y súbitamente acababa de asaltarlo no tardó en ser morigerado y rectificado por la razón y una autodisciplina practicada desde sus años juveniles” (Mann, 1999, 19).

\begin{tabular}{|c|c|c|c|c|}
\hline Qevista Dialectus & Ano 10 & n. 21 & Janeiro - Abril 2021 & p. $97-115$ \\
\hline
\end{tabular}


explica que la Stimmung se extiende más allá de un yo al que afecta directamente, y da como ejemplo el paisaje: el héroe de Mann se envuelve de una atmósfera de alegría en la Venecia que habita Tadzio. Su estancia allí es feliz. ${ }^{40}$ Aschenbach se encuentra permanentemente asediado por el temor que es revertido por momentos con pasajes a una actitud activa; así decide emprender el viaje, permanecer en el hotel o teñirse el cabello. En todos estos casos, la acción frente a lo que vendrá, algo totalmente inesperado y desconocido, lo dispone interiormente de manera positiva y lo lleva a tomar decisiones basadas en el deseo de lo aún no vivido: la espera afectiva frente a lo exterior es afirmativa. En este sentido, el burgués decadente también es atravesado por la espera positiva, espera que implica un contenido mayor que el de su representación.

La narración de la muerte en Der Tod in Venedig, además, muestra de manera paradigmática el pasaje del miedo a la esperanza, ${ }^{41}$ aquí la angustia no es un estado existencial definitivo, ${ }^{42}$ sino un momento negativo del estado afectivo; como sostiene Bloch todavía determinado por la Stimmung y en suspenso por lo indeterminadado de su objeto (Bloch 1993, 125s.). A diferencia de la desesperación, absolutamente negativa y vinculada a un estado de ánimo que lleva consigo algo definitivo y definido, la angustia de Aschenbach se trastoca en su contrario positivo constantemente en la novela corta de Mann. El personaje de la narración pasa de uno a otro estado de manera incesante y la juventud de Tadzio, juventud anhelada para sí mismo, se asocia en Aschenbach a una espera que supera cada representación dada al protagonista y por ello lo lleva a la acción: la última frase del penúltimo párrafo resume el comportamiento del protagonista y enfatiza ese carácter práctico: "Und, wie so oft, machte er sich auf, ihm zu folgen" (Mann, 1960, 524).$^{43}$ La permanencia en la ciudad no es por ello una

40 "Der wohlige Gleichtakt dieses Daseins hatte ihn schon in seinen Bann gezogen, die weiche und glänzende Milde dieser Lebensführung ihn rasch berückt. [...] Nur dieser Ort verzauberte ihn, entspannte sein Wollen, machte ihn glücklich" (Mann, 1960, 487) ("La placentera regularidad de esa existencia no tardó mucho en hechizarlo; pronto se sintió fascinado por la dulce y brillante placidez de aquel tren de vida. [...] Sólo ese espacio era capaz de cautivarlo, de relajar su voluntad y hacerlo sentirse feliz") (Mann, 1999, 70).

${ }^{41}$ Una lectura que, desde otra perspectiva, vincula muerte y esperanza se encuentra también presente en un ensayo temprano de Walter Benjamin sobre Die Wahlverwandtschaften. El filósofo berlinés se detiene allí en la frase “"Die Hoffnung fuhr wie ein Stern, der vom Himmel fällt, über ihre Häupter weg”" (GS 1/1: 200) ("'La esperanza pasó sobre sus cabezas como una estrella fugaz"' (Benjamin, 2000, 101)) para interpretar la Novelle de Goethe. La referencia no carece de importancia en este contexto dado que el estudio fundado en fuentes de Herbert Lehnert sostiene que Mann habría leído esta obra de Goethe durante el proceso de escritura de Der Tod in Venedig (Lehnert, 1964, 45).

${ }^{42}$ Son múltiples los estudios sobre la decadencia y la muerte en la Novelle. Entre otros, Shookman se refiere a los trabajos de los años treinta de Lydia Baer, Hans Kasdorff y Fritz Nolte. También menciona Shookman el análisis de 1966 de Jeannette Lander quien enfatizaría el carácter existencial de la obra; según esta interpretación la novela corta de Mann habría anticipado "el existencialismo articulado por Martin Heidegger" (Shookman, 2003, 123).

43 "Y, como tantas otras veces, se dispuso a seguirlo" (Mann, 1999, 116).

\begin{tabular}{|c|c|c|c|c|}
\hline Q & Ano 10 & n. 21 & Janeiro - Abril 2021 & p. $97-115$ \\
\hline
\end{tabular}




\section{LA DECADENCIA Y EL AMANECER: UN ANÁLISIS BLOCHIANO... \\ María Belforte}

entrega a los instintos primitivos y decadentes de la burguesía sin salida, sino la aparición de lo utópico perdido tras el abandono burgués de los ideales que le dieron origen como clase ascendente. La atmósfera de embriaguez que rodea a Aschenbach es signo de que la aparición del afecto de espera positivo es interpretada regresivamente: la reaparición de lo que aún no existe es para la burguesía algo indecente e indecoroso. Pero en la obra se filtra, se presenta con su marca existencial, como afecto que persiste porque es propiamente humano. También la relación del peligro y la salvación, que Bloch recupera del poema de Hölderlin posee un lugar central en la narración y se plasma en la imagen final en la que incluso el viejo Aschenbach se dispone a salvar al joven Tadzio en la playa: "Entsetzt wollte Aschenbach zur Rettung aufspringen, als der Gewalttätige endlich sein Opfer freigab” (Mann, 1960, 524). ${ }^{44}$

Así, la muerte (Der Tod) que se indica en el título mediante el artículo definido puede interpretarse como una determinación específica que le otorga la esperanza, aquella que Bloch llama "das positiv-dialektische Wendemoment an, dem die Furcht der Todesstelle verschwunden ist" (Bloch, 1993, 127). ${ }^{45}$ Aschenbach muere precisamente en el entrecruzamiento de miradas con la figura amada en el horizonte. Mann llama allí a Tadzio "der bleiche und liebliche Psychagog", es decir, el que conduce el alma hacia la muerte. Esta referencia a la figura mítica de Hermes, que en la escultura clásica se lo representaba precisamente como "un bello efebo de mirada pícara" (García Gual, 2003, 177) es acompañada por adjetivos positivos que describen al dios en el umbral; ese pasaje hacia la muerte, en la ciudad de Venecia, de la mano de Tadzio, es un pasaje dominado por el afecto de la espera positivo, un pasaje sin angustia ni temor. La decadencia de Aschenbach anhela la juventud de Tadzio y en su narración, Mann cuenta cómo su protagonista alcanza una muerte en la que el sujeto pierde el temor y la angustia de su existencia burguesa.

\section{Conclusiones}

Siguiendo la teoría blochiana de los afectos, Der Tod in Venedig se convierte así en una novela corta en la que se muestra el pasaje del miedo a la esperanza y la consecuente resignificación de la muerte. La desaparición de los afectos negativos frente al acontecer del final de la vida se da con ese pasaje. Así, la machtgeschützte Innerlichkeit de la burguesía, del

\footnotetext{
44 "Aterrado, Aschenbach se disponía a acudir en su ayuda, cuando el violento soltó finalmente a su presa" (Mann, 1999, 115).

45 "el punto decisivo dialéctico-positivo en el que ha desaparecido el miedo al momento de la muerte" (Bloch, 2007, 146)

\begin{tabular}{|l|l|l|l|l|}
\hline Rovista Dialectus & Ano 10 & n. 21 & Janeiro - Abril 2021 & p. 97 - 115 \\
\hline
\end{tabular}
}




\section{LA DECADENCIA Y EL AMANECER: UN ANÁLISIS BLOCHIANO...}

sí mismo, de la interioridad, central en la narración de Mann, mostraría de acuerdo con esta lectura, que incluso en una fase de decadencia de la cultura burguesa de preguerra, la subjetividad posee la latencia de lo utópico. Aunque esa presentación aparezca rodeada y disfrazada con elementos míticos y embriagadores que muestran el carácter regresivo en el que esa interioridad se inserta. Que la intencionalidad de Mann envuelva ese afecto positivo que constituye al personaje de Aschenbach con la máscara de la embriaguez dionisíaca, tópico recurrente de la literatura del Imperio, e interprete esa determinación de la interioridad como un frenesí destructivo, como muestran reiterados pasajes de la Novelle, habla de la conformación ideológica burguesa pero no de la constitución afectiva humana. Según esta lectura, las determinaciones histórico-sociales de la obra, la impronta de la decadencia burguesa en el período previo a la primera guerra no habrían apartado todo vestigio utópico de la representación narrativa.

En una entrevista de 1913, Mann sostuvo: “Im 'Tod in Venedig' wollte ich einen Mann vostellen, der auf dem Gipfel des Ruhmes, der Ehrung, der Berühmtheit und des Glücks keine Zuflucht in der Kunst findet, sondern an einer unüberwindlichen Leidenschaft körperlich und seelisch zugrunde geht...", ${ }^{46}$ y en este sentido, sostiene allí Mann, el tema del amor homosexual no resultaría lo esencial de su libro (Hansen; Heine, 1983, 37). Esta declaración del escritor reforzaría la impronta existencial de su obra de 1912 y la presencia fundamental de los afectos en la construcción del personaje principal. Se trata de un intento de salida de ese refugio (Zuflucht) de la interioridad. Precisamente, Bloch sostiene la percepción del afecto como pasión o aflicción cuando el hombre se vuelca a uno solo de los movimientos del ánimo (Gemütsbewegungen): "wirft der ganze Mensch sich in einem einzigen Affekt, so wird dieser zur Leidenschaft" ${ }^{47}$ (Bloch, 1993, 77).

Según una lectura utópica, guiada por la teoría de los afectos blochiana, la Novelle presenta la esperanza del protagonista desde una perspectiva burguesa, es decir, enmarcada por ideales morales desfiguradores y regresivos, por esa coraza rígida del "formalismo de la ética del deber", como la denomina Lukács. Pero estos elementos, si bien disminuyen la función utópica de la obra, no la hacen desaparecer.

46 "En La muerte en Venecia, quise mostrar un hombre que en la cima de la celebridad, de la veneración, de la fama y de la buena fortuna no puede encontrar refugio en el arte, sino que se hunde corporal y anímicamente en una pasión invencible" (la trad. es mía).

47 "si el hombre se concentra en un solo afecto, éste se convierte en pasión" (Bloch, 2007, 99). 
En su Ästhetik, Lukács cita precisamente a Mann para indicar la absorción del sentimiento vital (Lebensgefühl) por parte de la opacidad desesperanzada de la decadencia capitalista:

“[...] Dem einzelnen Menschen mögen mancherlei persönliche Ziele, Zwecke, Hoffnungen, Aussichten vor Augen schweben, aus denen er den Impuls zu hoher Anstrengung und Tätigkeit schöpft; wenn das Unpersönliche um ihn her, die Zeit selbst der Hoffnungen und Aussichten bei aller äußeren Regsamkeit im Grunde entbehrt, wenn sie sich ihm als hoffnungslos, aussichtslos und ratlos heimlich zu erkennen gibt, und der bewußt oder unbewußt gestellten, aber doch irgendwie gestellten Fragen nach einem letzten, mehr als persönlichen, unbedingten Sinn aller Anstrengung und Tätigkeit ein hohles Schweigen entgegensetzt, so wird gerade in Fällen redlicheren Menschentums eine gewisse lähmende Wirkung solchen Sachverhalts fast unausbleiblich sein, die sich auf dem Wege über das SeelischSittliche geradezu auf den physischen und organischen Teil des Individuums erstrecken mag [...]" (Lukács, 1963, 170s.). ${ }^{48}$

La filosofía blochiana incorpora el concepto de Erwartungsaffekte y pone en juego así en su análisis el componente existencial en la relación del sujeto con su medio histórico y social. Con esta introducción, que reconoce críticamente en Heidegger un exponente, se resignifica la condición ontológica del ser social del individuo que, afectado primariamente por los Triebgehfülen, posee la capacidad de proyectar un horizonte más allá del recuerdo y de la angustia. La regresividad de las imágenes dionisíacas y la interpretación del sueño como condena y quiebre de la "Haltung" ética de Aschenbach como representante de la burguesía en decadencia no destruyen los componentes utópicos que aparecen en Der Tod in Venedig, sino que, por el contrario, muestra, por contraste, la presencia de sentimientos o afectos hacia lo por venir que no existió ni existe aún, pero que se encuentra latente en los hombres como seres insatisfechos.

\section{Referencias bibliográficas}

BENJAMIN, W. Las afinidades electivas de Goethe. En: -, Dos ensayos sobre Goethe. Traducción de Graciela Calderón y Griselda Mársico. Barcelona: Gedisa, 2000, 11-102.

BENJAMIN, W. Gesammelte Schriften = [GS]. Tiedemann, R., Schweppenhäuser, H. (eds.), 7 tomos. Frankfurt a/M: Suhrkamp, 1972-1989.

48 ، “ [...]. Cada persona suele tener a la vista diversos fines personales, objetivos, esperanzas, perspectivas, de las que recibe impulso para mayor esfuerzo y actividad; mas si lo impersonal que le rodea, la época misma, carece en el fondo de esperanzas y perspectivas, por grande que sea su agitación, y si se le revela secretamente como desesperanzada, sin perspectiva ni consejo, y opone un silencio vacío a las preguntas, puestas con consciencia o sin ella, pero siempre puestas de algún modo, que inquieren el sentido último, más que personal, absoluto, de todo esfuerzo y actividad, entonces, precisamente en casos de más honrada humanidad, será casi inevitable cierto paralizador efecto de la tal situación, el cual, por el camino de lo anímico y moral, puede incluso alcanzar la parte física y orgánica del individuo. [...]"” (Lukács, 1966, 180-181). El pasaje citado por Lukács pertenece a Der Zauberberg (Mann, 1988, 36-37).

\begin{tabular}{|c|c|c|c|c|}
\hline Q Rovista Oialeatus & Ano 10 & n. 21 & Janeiro - Abril 2021 & p. $97-115$ \\
\hline
\end{tabular}


BLOCH, E. El principio esperanza 1. Traducción de Felipe González Vicén. Madrid: Trotta, 2007.

BLOCH, E. El principio esperanza 2. Traducción de Felipe González Vicén. Madrid: Trotta, 2006.

BLOCH, E. Das Prinzip Hoffnung, 3 tomos. Frankfurt a/M: Suhrkamp, 1993

BLOCH, E. Geist der Utopie. Zweite Fassung. Frankfurt a/M: Suhrkamp, 1985.

BORCHMEYER, D. Décadence. En: NIEMEYER, CH. (ed.). Diccionario Nietzsche. Conceptos, obras, influencias y lugares. Traducción de Iván de los Ríos, Sandra Santana, José Luis Puertas y José Planells. Madrid: Biblioteca Nueva, 2012, 138-140.

GARCÍA GUAL, C. Diccionario de mitos. Madrid: Siglo XXI, 2003.

HANSEN, V.; HEINE, G. (eds.). Frage und Antwort. Interviews mit Thomas Mann, 19091955. Hamburgo: Albrecht Knaus, 1983.

LEHNERT, H. Thomas Mann's Interpretations of Der Tod In Venedig and Their Reliability. Rice Institute Pamphlet - Rice University Studies, 50, no. 4, 1964, 41-60.

LUKÁCS, G. Über Preußentum. En: -, Schicksalswende. Beiträge zu einer neuen deutschen Ideologie. Berlín: Aufbau, 1948, 68-94.

LUKÁCS, G. Georg Lukács Werke. Band 11: Ästhetik Teil 1: Die Eigenart des Ästhetischen. Neuwied y Berlín: Luchterhand, 1963.

LUKÁCS, G. Auf der Suche nach dem Bürger. En: -, Georg Lukács Werke. Band 7: Deutsche Literatur in zwei Jahrhunderten. Neuwied y Berlín: Luchterhand, 1964, 505-534.

LUKÁCS, G. Estética 1. La peculiaridad de lo estético. Vol.1. Traducción de Manuel Sacristán. Barcelona: Grijalbo, 1966.

LUKÁCS, G. A la búsqueda del burgués. En: -, Thomas Mann. Traducción de Jacobo Muñoz. Barcelona: Grijalbo, 1969, 13-52.

LUKÁCS, G. Franz Kafka oder Thomas Mann? En: -, Essays über Realismus. Neuwied y Berlín: Luchterhand, 1971, 500-550.

LUKÁCS, G. ¿Franz Kafka o Thomas Mann? En: -, Significación actual del realismo crítico. Traducción de María Teresa Toral, revisada por F. Álvarez. México: Era, 1984, 58-112.

LUKÁCS, G. Sobre el prusianismo. En: Inter Litteras № 1 (2019), 148-172. Traducción e introducción de Mariela Ferrari. Disponible en: https://doi.org/10.34096/interlitteras.n1.7227.

MANN, TH. Der Tod in Venedig. En: -, Gesammelte Werke. Band VIII: Erzählungen, Fiorenza, Dichtungen. Oldenburg: Fischer, 1960, 444-525.

\begin{tabular}{|c|c|c|c|c|}
\hline Qovista Dialectus & Ano 10 & n. 21 & Janeiro - Abril 2021 & p. $97-115$ \\
\hline
\end{tabular}


MANN, TH. Der Zauberberg. Frankfurt a/M: Fischer, 1988.

MANN, TH. Muerte en Venecia. En: -, Muerte en Venecia / Mario y el mago. Traducción de Juan del Solar [para la primera obra] y Nicanor Ancochea [para la segunda obra]. Barcelona: Plaza \& Janés Editores, 1999, 14-116.

MAYER, H. Thomas Mann o el punto crítico. En: -, La literatura alemana desde Thomas Mann. Traducción de M. P. Lorenzo. Madrid: Alianza, 1970, 8-26.

ROSSI, F. Der Tod in Venedig. En: BLÖDORN, A.; MARX, F. (ed.). Thomas Mann Handbuch. Leben - Werk - Wirkung. Stuttgart: Metzler, 2015, 126-130.

SIEBERS, J. Novum. En: DIETSCHY, B.; ZEILINGER, D.; ZIMMERMANN, R. (eds.). Bloch-Wörterbuch: Leitbegriffe der Philosophie Ernst Blochs. Berlín: De Gruyter, 2012, 412- 416.

SHOOKMAN, E. Thomas Mann's Death in Venice. A Novella and its Critics. Nueva York: Camden House, 2003. 